\title{
A POESIA: ESTRATÉGIAS PARA EXPERIMENTAR E FRUIR EM SALA DE AULA
}

\author{
POETRY: STRATEGIES FOR EXPERIMENTING AND TAKING BLISS AT THE CLASSROOM
}

\author{
LA POESÍA: ESTRATEGIAS PARA LA PRÁCTICA Y EL GOCE EN EL AULA
}

\author{
SILVEIRA, Rosilene de Fátima Koscianski da ${ }^{1}$ \\ DEBUS, Eliane Santana Dias ${ }^{2}$ \\ AZEVEDO, Fernando José Fraga de ${ }^{3}$
}

\begin{abstract}
RESUMO
A poesia é intrínseca ao homem. Na sua origem histórica, o termo poesia provém da palavra grega poiein, que significa fazer. Desde uma idade precoce a criança manifesta um fascínio pelos jogos de linguagem e pela sua vertente sonora e rítmica. Quanto mais cedo meninos e meninas encontram-se e interagem com essa forma de linguagem, maiores são o grau de familiaridade e as possibilidades de se estabelecer uma relação prazerosa e fecunda entre ambos. O papel da escola consiste em promover e potencializar o encontro "poesia e criança". O presente texto objetiva, de modo geral, ampliar a reflexão acerca da presença da poesia na escola; e, especificamente, dialogar sobre as estratégias que possibilitam experimentar e fruir a poesia no chão da sala de aula, partindo da interlocução com diferentes pesquisadores da temática. Esse estudo vai também à escola, no contexto português, para estabelecer um diálogo com os docentes que atuam nos anos iniciais do Ensino Básico sobre: o modo de inserção da poesia neste espaço-tempo; a frequência com que o texto poético transita na sala de aula; e, principalmente, para buscar destes mediadores o compartilhamento de suas experiências reais de trabalho com o texto poético. Destacamos a relevância de as estratégias de trabalho com o texto poético se tornarem presentes na formação inicial e continuada dos professores. Nossa reflexão aponta num sentido propositivo, buscando enfatizar as estratégias que possibilitam experimentar, fruir e criar poesia no chão da sala de aula e cujo trato empírico leva em conta os aspectos estético, linguístico e literário que consubstanciam esta forma de linguagem.
\end{abstract}

Palavras-chave: Poesia. Estratégias. Fruição. Autoria.

\section{ABSTRACT}

Poetry is intrinsic to man. In its historical origin, the term "poetry" proceeds from the Greek word poiein, which means "to make". Since an early age, children manifest fascination for language games and its sonic and rhythmical dimension. The earlier boys and girls meet and interact with this form of language, the higher their level of familiarity and the possibilities of establishing a pleasant, fertile relationship between them. The role of the school consists in promoting and potentiating the poetry-and-child encounter. This text aims, largely, to increase reflection on the presence of poetry in school and, specifically, to start a dialogue about the strategies that allow to experiment and take bliss in poetry on the floor of the classroom, beginning with an interlocution with different researchers on this theme. This study also goes to school, in the Portuguese context, to establish a dialogue with the teachers of the early years of primary school about: how to insert poetry into this space-time; how often poetic texts transit through the classroom; and, especially, how to get those mediators to share their real work experiences with poetic texts. We stress the significance of the strategies of work with poetic texts being present in the early and later stages of teachers' training. Our reflections point to a propositional direction, seeking to emphasize strategies that enable the students to experiment, take bliss, and create poetry on the floor of the classroom and whose empiric treatment takes into account the aesthetic, linguistic, and literary aspects consubstantiate such language form.

Keywords: Poetry. Strategies. Bliss. Authorship.

\footnotetext{
1 Universidade do Sul de Santa Catarina - UNISUL - Tubarão - Santa Catarina - Brasil.

2 Universidade Federal de Santa Catarina- UFSC - Florianópolis - Santa Catarina - Brasil.

3 Universidade do Minho - UMINHO - Braga - Portugal.
} 


\section{RESUMEN}

La poesía es intrínseca al hombre. En su origen histórico, el término poesía proviene de la palabra griega poiein, que significa "hacer". Desde edad precoz el niño manifiesta una fascinación por jugar con el lenguaje y por su aspecto sonoro y rítmico. Cuanto más temprano los niños y niñas se encuentran e interactúan con dicha forma de lenguaje, mayores son el grado de familiaridad y las posibilidades de establecer una relación placentera y fecunda entre ambos. El papel de la escuela consiste en promover y potenciar el encuentro poesía-niño. El presente texto tiene el objetivo general de ampliar la reflexión sobre la presencia de la poesía en la escuela; y, específicamente, dialogar sobre las estrategias que hacen posible la práctica y el goce de la poesía dentro del aula, partiendo de la interlocución con distintos investigadores de la temática. Este estudio también va a la escuela, en Portugal, para establecer un diálogo con los docentes que actúan en los años iniciales de la Enseñanza Básica sobre: el modo de inserción de la poesía en ese espacio-tiempo; la frecuencia con que el texto poético circula en el aula; y, principalmente, para buscar que estos mediadores compartan sus experiencias reales de trabajo con el texto poético. Ponemos de relieve la relevancia de que las estrategias de trabajo con el texto poético estén presentes en la formación inicial y continuada de los profesores. Nuestra reflexión apunta en un sentido propositivo, intentando enfatizar las estrategias que hagan posible practicar, gozar y crear poesía en el aula y cuyo trato empírico tome en cuenta los aspectos estético, lingüístico y literario consubstanciales a esta forma de lenguaje.

Palabras clave: Poesía. Estrategias. Goce. Autoría. 


\section{INTRODUÇÃO}

A poesia é inerente ao homem. Na sua origem histórica, o termo poesia provém da palavra grega poiein, que significa fazer. Ribeiro (2007), falando da poesia, refere-se a uma metalinguagem que tem o seu valor intrínseco:

encontra o seu fundamento axiológico na racionalidade própria da condição humana e situa-se para além da mera comunicação funcional, enxerta-se numa antropologia que possibilita ao Homem dizer-se inteiro e, enquanto tal, configura-se numa representação universal do mundo [...]. (RIBEIRO, 2007, p. 59)

Ora, desde uma idade precoce que a criança manifesta um fascínio pelos jogos de linguagem e pela sua vertente sonora e rítmica. Bocheco (2002, p. 22) faz referência a um "abraço mágico" que acontece entre a poesia e a infância e por meio do qual, no reino da sua intimidade, a criança recolhe "alpiste pro sonho, enriquecendo-se e elaborando vivências". Quanto mais cedo meninos e meninas encontram-se e interagem com essa forma de linguagem, maiores são o grau de familiaridade e as possibilidades de se estabelecer uma relação prazerosa e fecunda entre ambos. Porém, o tratamento que a escola faz dela é, muitas vezes, equivocado, gerando um progressivo afastamento do leitor face a essa categoria textual (SOUZA, 2006; MELO, 2011).

Averbuck (1985, p. 65) demonstrou o quanto a poesia entra na escola marginalmente, lamentando que "a sala de aula, antes de ser o território da inventividade, é, na maioria das vezes, o lugar onde se anulam as possibilidades de criação e inovação". Em um contexto como o tratado pela autora, a escola, que deveria potencializar e intensificar as interações da criança com o texto poético, "via de regra, é a mais apressada em cortar os laços lúdicos com o mundo em nome da norma, da regra, da urgência da matéria curricular oficial" (BOCHECO, 2002, p. 23).

Por outro lado, chegamos a um momento no qual se deixa de lado o plano das lamentações e em que começamos a propor (e experimentar) algumas estratégias de trabalho bastante fecundas que aproximam a criança (o jovem e o adulto) do texto poético. Podemos perceber que a última década em especial vem impulsionando a "poesia na escola" e mudando um pouco o cenário de ausências e equívocos. A poesia foi contextualizada no âmbito da linguagem, vista e exercitada (ouvida, fruída, criada) no campo literário como produto humano, desconstruindo, em parte, a aura de inacessibilidade que a acompanhou em alguns modos de conceituá-la.

Esse avanço percebido é resultado de alguns fatores que a perpassam, dentre os quais destacamos: 1) políticas públicas de leitura que fazem chegar às unidades escolares acervos de qualidade, por meio dos Planos Nacionais de Leitura, tanto no Brasil quanto em Portugal (BALÇA; SOUZA, 2012); 2) a inserção da temática em alguns cursos de Pedagogia, pois, como esclarecem Debus e Cintra (2012, p. 157): "pensar no poema para crianças implica pensar sobre a mediação dos professores dessas crianças"; e 3) o engajamento crítico e criativo de (alguns) professores e professoras que recriam estratégias de trabalho com o texto poético no chão das salas de aula. 
No sentido ora enunciado, vemos que as críticas e constatações apresentadas pelos pesquisadores resultaram em algumas ações concretas. Podemos perceber que nos dias atuais a poesia está contemplada de modo significativo e qualificado nos acervos que adentram as escolas e as salas de aula, não apenas por meio dos livros indicados nas listas atualizadas anualmente no Plano Nacional de Leitura - PNL (Portugal) e Programa Nacional Biblioteca da Escola - PNBE (Brasil), mas igualmente pelas diretrizes propostas sobre a forma de trabalho com o referido acervo. A novidade, segundo Balça e Souza (2012), ao falar do contexto português, é a obrigatoriedade de ler e trabalhar diariamente os diferentes gêneros com as crianças da Educação Infantil e dos anos iniciais da Educação Básica. Esta obrigatoriedade, de certa forma, vem impulsionando docentes a (re)significar as estratégias conhecidas e a criar outras formas de trabalho com o texto poético, especialmente aqueles com potencial de recepção infantil.

Com o presente texto objetivamos, de modo geral, ampliar a reflexão acerca da presença da poesia na escola e, especificamente, dialogar sobre as estratégias que possibilitam experimentar e fruir a poesia no chão da sala de aula, compartilhando-as. Para atingir estes objetivos, além da interlocução com pesquisadores da temática, vamos também à escola para estabelecer um diálogo com os docentes que atuam nos anos iniciais do Ensino Básico sobre: o modo de inserção da poesia neste espaço-tempo; a frequência com que o texto poético transita na sala de aula; e, principalmente, saber se estes mediadores poderiam compartilhar suas experiências de trabalho com o texto poético. No que se refere à formação de professores, estratégias de trabalho com o texto poético se tornam presentes em sua formação inicial e continuada, tal como Debus e Cintra (2012) exemplificam, apresentando atividades que foram realizadas no curso de Pedagogia da UFSC, numa metodologia que também pode ser "experimentada" com crianças de diferentes idades. Nossa reflexão busca, num sentido propositivo, dar ênfase às estratégias que possibilitam experimentar, fruir e criar poesia no chão da sala de aula, levando em conta a natureza estética, linguística e literária da linguagem poética.

\section{A MAIS-VALIA DA POESIA}

Diversos investigadores têm atestado as vantagens de uma interação precoce da criança com os textos poéticos, mesmo antes de esta ser alfabetizada (BASTOS, 1999; RAMOS, 2007). Ballesteros (1993) considera que a poesia reivindica um papel e um significado importantes para a descoberta do poder expressivo e comunicativo da palavra. Cerrillo (2007), por outro lado, assinala os valores linguístico-literários de que ela é portadora e a sua utilidade no período escolar. Ribeiro (2009, p. 68) sublinha o grau de desfamiliarização que a poesia provoca, ao desencadear "uma modificação e alteração dos conceitos e sentimentos". Domingues e Ebert (2014) enfatizam a relevância do contato da criança com o texto poético. Graças a ele, a criança explora, de modo lúdico, os múltiplos sentidos durante o processo de leitura do poema, podendo integrar-se plenamente numa cultura de leitura. Como explicitamente o referem: 
estratégias interessantes, atraentes e condizentes com os propósitos e as demandas do processo de alfabetização, tornando, também, a leitura algo prazeroso. (DOMINGUES; EBERT, 2014, p. 54)

No fundo, a poesia encerra um capital cultural (BOURDIEU, 1994), possuindo um valor pedagógico e educativo. Este reconhecimento, solidificado no âmbito acadêmico e científico, começa a despontar não apenas no discurso docente, mas efetivamente em atividades realizadas no chão das salas de aula. Conforme anunciamos, fomos à escola para ver de perto, as atividades com poesia que os professores dos anos iniciais do ensino básico realizam. Foram visitadas duas escolas em Braga, Portugal, as quais vamos chamar de Escola 1 e Escola 2. As visitas à Escola 1 ocorreram em 18 de dezembro de 2015 e 23 de fevereiro de 2016. A visita e a conversa com os professores da Escola 2 aconteceram no dia 04 de fevereiro de 2016. Outras visitas anteriores foram necessárias nas duas escolas para que pudéssemos agendar/planejar os encontros com as professoras e com os coordenadores. As mesmas perguntas, em forma de entrevista semiestruturada, foram feitas aos profissionais das duas escolas. Após contatos iniciais, foram marcados encontros e pudemos ouvir os docentes acerca da relevância do texto poético na escola e principalmente sobre as estratégias de trabalho que estes utilizam. Apresentamos aos entrevistados a síntese da proposta de pesquisa de Doutorado em Educação (em andamento na época) e questões acerca do trabalho com a poesia na escola. Na primeira unidade escolar participaram quatro professoras e um professor e o encontro foi gravado em áudio, durou em torno de duas horas/aula. A segunda unidade de ensino teve a participação de cinco professoras. Também teve uma duração aproximada de duas horas/aula. Nesta escola as docentes preferiram conversar sobre as atividades sem gravação de áudio, nos contar sobre os modos de inserir o texto poético no contexto da sala de aula e enviar (por e-mail) uma síntese com respostas para as questões levantadas. Recebemos o material produzido pelas docentes em seguida.

Uma das professoras entrevistadas, ao descrever sua experiência de trabalho com poesias, afirmou: "O texto poético pode ser trabalhado na sala de aula em qualquer momento; se este surgir no manual escolar, se este surgir nas obras de Educação Literária [...]. Pode também ser trabalhado em obras de autores convidados a visitar a escola." (Prof. ${ }^{a}$ A, fev. 2016) ${ }^{4}$. Esta professora compreende que a poesia precisa estar presente na sala de aula de modo intensivo, afirmando que:

\begin{abstract}
A poesia pode ser trabalhada a toda a hora [...]. Uma simples quadra para a motivação da aprendizagem de um determinado conteúdo, uma lenga-lenga, a letra de uma canção podem perfeitamente ser momentos dedicados à poesia. Desta forma, esta aproximação com a linguagem poética tem como objetivo familiarizar o aluno com a poesia, para que este cada vez mais tenha prazer em ler e ouvir poemas e, sobretudo, para que se sinta motivado a expor as suas emoções, dar liberdade de criar, brincar com as palavras, fluir com a imaginação. (Prof. ${ }^{a} A$, fev. 2016).
\end{abstract}

Novais (2013, p. 38) destaca a importância do professor e da professora enquanto mediadores responsáveis "pela formação de leitores de poesia", pois, para eles serem capazes "de se posicionar

\footnotetext{
4 As participantes não serão identificadas nominalmente. Trazemos a contribuição de quatro professoras identificando-as como: A, B, C e D.
} 
diante das inúmeras escolhas demandadas em sala de aula, é muito importante que constitua[m] um repertório amplo de saberes literários". Isso inclui também conhecer as formas, os elementos constitutivos e as figuras de linguagem que caracterizam a poesia não como um conhecimento fim, ou para ser "repassado" aos alunos, mas como recurso que pode auxiliar tanto na familiarização quanto na apreciação desta forma de linguagem. Desse modo, à medida que professores e alunos vão interagindo com as diferentes formas poéticas, cotidianamente, vão ampliando seu repertório, aprimorando os critérios de escolha e, contextualmente, se apropriando da organização estrutural do poema, reconhecendo seus elementos constitutivos. Tão importante quanto trazer a poesia para a sala de aula é tratá-la como poesia, com as peculiaridades que a constituem.

Outra professora entrevistada destacou os diferentes suportes que trazem a poesia à sala de aula contemporânea. Citou desde o "velho" livro didático (como é conhecido no Brasil), ou manual da escola (como é chamado em Portugal), importante veículo de socialização de poemas escritos por diferentes poetas, até o "computador, que hoje em dia tem variadíssimos sites com obras literárias indicadas para os nossos alunos" (Prof. ${ }^{a}$ B, fev. 2016). Nesse sentido, também podemos vislumbrar maiores possibilidades de escolarização da poesia, que, segundo Novaes (2013, p. 37), "sem prejuízo de outras possíveis intenções [...] poderia se pautar por, pelo menos, três funções básicas: servir como suporte à alfabetização, como auxílio à formação da leitura em geral e como fomento ao letramento literário". Estas razões apontadas pelo autor mostram a relevância da sistematização do trabalho com a poesia na escola. Porém, uma sistematização que vai além de contemplar o texto poético nos currículos padronizados e que depende da ação crítica e engajada dos professores e professoras. São eles e elas que planejam e efetivamente levam a poesia para a sala de aula. Sobre isso, assim se posiciona a professora B:

Normalmente tento diversificar os textos trabalhados e pelo menos uma vez por semana incluo a poesia. Desde muito cedo devemos promover nas crianças o gosto pela leitura. Cabe-nos ajudálas a desenvolver essa paixão, começando por Ihes mostrar a diversidade de textos que existem e fazer com que elas se apaixonem pela leitura, seja qual for o tipo de texto. Devemos selecionar textos que mexam com as emoções das crianças para que elas os sintam. As crianças começam a viver outras vidas, através da leitura. (Prof. ${ }^{a} \mathrm{~B}$, fev. 2016)

O trabalho com o texto poético ganha maior consistência quando está nas mãos de mediadores apreciadores da poesia, leitores que compartilham o interesse e a afeição pela leitura poética. Parr e Campbell (2006) enfatizam que docentes e alunos precisam entender o valor da poesia e que, para que as crianças possam apreciar e valorizar essa linguagem, os professores precisam demonstrar na prática o seu apreço por esta forma literária, seja com o conhecimento compartilhado sobre poesia e suas diversas formas, seja pela leitura e escrita de poemas na sala de aula. A inserção frequente da poesia na escola contribui para a formação do leitor, decorrendo num processo de letramento literário não apenas da criança, mas igualmente do seu mediador.

Perguntamos às professoras sobre a frequência da poesia na escola, se há um momento específico destinado ao texto poético, como um dia na semana ou no mês previsto no planejamento da 
instituição para trabalhar com poesia. A professora B não respondeu pela escola, como planejamento coletivo, mas por sua agenda de trabalho com sua turma:

\footnotetext{
Não tenho um dia esnecífico mas tento incluir um texto noético nelo menos uma vez nor semana. Gosto de trabalhar a poesia. pois a poesia brinca com as palavras. explora a sonoridade o ritmo as rimas, as repetições, a musicalidade, o que agrada os alunos desta idade. (Prof. ${ }^{a}$ B, fev. 2016).
}

Bordini (2016, [s.p.]) explica que ler poesia é uma habilidade que pode ser ensinada e aprendida nas diferentes etapas escolares, até depois da universidade. Para a autora: "De início, a questão é aprimorar o ouvido para as sonoridades e suas repetições, o que a criança consegue ao ouvir poemas desde pequena. Num segundo momento, cabe marcar ritmos e perceber seus retornos, constituindo os versos." Nos primeiros anos escolares cabe explorar bastante a modalidade oral na leitura, na fruição e na criação poética e, como afirmou a professora $\mathrm{B}$, isso agrada bastante as crianças desta idade. A docente se referia a meninos e meninas com sete ou oito anos de idade que, de modo geral, estão familiarizados com algumas formas poéticas que conheceram na Educação Infantil e no espaço familiar. Parr e Campbell (2006) ressaltam que as crianças ouvem canções de ninar desde muito pequenas e experimentam poemas antes de entrarem na escola, cantando versos ao pular corda e batendo palmas ao ritmo de poemas e canções. Para os autores, se as crianças podem cantar e recitar poemas, em breve serão capazes de ler; e se podem ler, em breve serão capazes de escrevê-los, pois a linguagem poética é diversão e ritmo, envolve a criança e cativa seu interesse.

\section{ESTRATÉGIAS PARA FRUIR A POESIA EM SALA DE AULA}

É nossa opinião que, para ser experimentada e fruída em sala de aula, o trabalho com a poesia deverá permitir, por um lado, escutá-la, isto é, fruir a dimensão significante da linguagem (PINHEIRO, 2002), e, por outro, assegurar a interação com um texto no qual a plurissignificação e a pluri-isotopia, fruto de uma organização complexa da linguagem resultante da articulação entre os elementos do conteúdo e os elementos da forma, são notas dominantes. Além disso, parece-nos igualmente imperioso que a sua presença em sala de aula não se restrinja a um momento efêmero ou pontual. $\mathrm{A}$ poesia, sendo expressão da emoção humana, deve estar presente em sala com "naturalidade". Linaberger (2004) sugere um plano de ação para levar a poesia à sala de aula. Nesse contexto, é relevante, entre outros aspectos, que o professor leia a grande e melhor poesia, procure questionar-se acerca do significado do que lê, tente escrever um poema, leia e partilhe, com outros, esse poema.

Rildo Cosson (2012) explica que o professor é regularmente o maior mediador entre o livro (ou o poema) e o aluno. A escola é um espaço-tempo privilegiado de experiência leitora para as crianças e jovens e algumas estratégias utilizadas na sala de aula procuram ampliar e potencializar a leitura da poesia de modo concreto e significativo. Elas têm início com uma seleção criteriosa de textos e autores, exigindo do professor mediador a formação adequada para fazê-la, mas também a disposição 
(ou seria a paixão?) pelo poético. Ângela Leite de Souza (2013) trata da necessidade de se estar "armado" de certa cultura poética para poder explorar com as crianças a potencialidade deste gênero textual. De posse de uma seleção adequada, observando critérios estéticos, linguísticos e literários a atenção se volta para os modos de inserir e lidar com o texto poético no espaço da sala de aula.

Renata Junqueira de Souza (2006, p. 51) defende que "um trabalho inicial com a poesia deve pautar-se pela sensibilização e pela descoberta desta ludicidade presente no jogo das palavras, criando um clima de exploração inventiva do texto poético". A roda de poesia, os saraus, a montagem de varais e murais poéticos na escola são algumas das formas utilizadas por professores que objetivam impulsionar a leitura da poesia e colocar os pequenos no circuito da fruição poética. $O$ problema se dá quando estas estratégias ficam limitadas ao domínio do eventual. A leitura poética exige mais do que eventualidade, pois ela precisa ser pensada como aprendizagem contínua e sistematizada. Além disso, em nossa compreensão, esse processo planejado e contínuo não forma apenas o leitor, mas um leitor-autor, convidado a "fazer" poesia. Mais do que as diferentes formas de leitura, a interação com poemas possibilita às crianças o ensaio de versos paralelos. Meninos e meninas realizam uma leitura autoral, ilustram os poemas que leem, transformam os poemas lidos em outros e podem ser convidados a escrever os seus próprios poemas.

A professora $C$ relata as estratégias de criação poética que utiliza na sala de aula. Ela afirma:

Na primeira semana de aula eu faço poemas. A criança tem que fazer uma quadra com o nome dela ou um acróstico. Acróstico é poesia. Para mim isso é poesia! Procuro estratégias que eles [os alunos] gostem. Tento buscar aquilo que me fez gostar de ler e escrever, que me motivava. Costumo pegar um poema e transformar o texto substituindo as palavras ou por sinônimos ou por antônimos, criando outro poema. Tem que ser em forma de brincadeira. Eu acho que é mais difícil escrever um poema do que escrever em prosa, parece que as crianças querem ser perfeccionistas. (Prof. ${ }^{a}$ C, dez. 2015).

Esta professora se diz apreciadora do texto poético e nos fala que utiliza diferentes estratégias de leitura e criação poética com as crianças. $O$ encontro com os docentes ocorreu em sua sala de aula, cujo mural exibia poemas escritos e ilustrados por seus alunos. A opção de construir estratégias de criação poética a partir da leitura de um poema é partilhada pela professora B, que explica sua forma de conduzir a atividade:

\begin{abstract}
Denendendo da poesia. umas vezes construímos balavras a partir de outras (brincamos com as balavras. construímos acrósticos). exploramos o som das mesmas, encontramos palavras com os mesmos sons, fazendo listas de palavras, fazemos rimas. As brincadeiras das crianças mostram claramente esse gosto especial pelos ritmos, pela musicalidade, pelas repetições, pelas aliterações, pelas onomatopeias, enfim, por diversas figuras de linguagem que muitas vezes, mesmo sem as reconhecer, as crianças fazem uso frequente nas suas atividades e brincadeiras. (Prof. ${ }^{a}$ B, fev. 2016).
\end{abstract}

A professora aponta duas questões importantes: a primeira, sobre o reconhecimento das características da linguagem poética, cuja aproximação textual se faz por meio das diferentes leituras. A segunda, a respeito do lúdico, que acompanha a relação "poesia e criança". Cunha (2013, p. 66) esclarece a diferença entre as características lírica e lúdica da poesia infantil: enquanto a lírica tende "a registrar ou capturar um sentimento, uma sensação, ou uma impressão, a poesia lúdica [...] 
costuma ser identificada com elementos exteriores ao poeta (ou ao seu 'eu lírico'): o jogo, a brincadeira, a festa". A experiência poética nesse jogo de linguagem acentua a natureza autoral da leitura, possibilitando a criação e a inventividade.

A professora $\mathrm{C}$ relata como convida seus alunos a experimentar poesia:

\begin{abstract}
Normalmente quando é poesia eu faço uma leitura para eles [os alunos] verem como ler a poesia, depois eles leem, dependendo do poema. Faço sempre algum jogo de leitura com o poema. Eles gostam muito, por exemplo, quando a gente começa a ler muito devagarinho e depois outra vez a ler muito mais depressa. Eles gostam, reagem muito bem, ao som, ao ritmo. Eles gostam de ouvir a rima e de viver a brincadeira. Eles conseguem "ver" a piada. É um bocadinho brincar com o texto. (Prof. ${ }^{a} \mathrm{C}$, dez. 2015)
\end{abstract}

"A poesia contém muitas figuras de estilo e permite fazer grandes alterações textuais, em que parece que o texto fica ao contrário", comenta a professora D (dez. 2015). Ela destaca a poética desse movimento de brincar e criar. Nas propostas de criação com as crianças, o ponto forte é o lúdico, o "brincar de ser poeta". Não se trata de buscar efeitos literário/poético nos textos (orais ou escritos) construídos pelas crianças (embora o insólito possa acontecer na poética da espontaneidade) ou voltar o foco para a estruturação da linguagem. Bordini (2016) explica que as regras do texto poético, como métrica, estrofação, rima, imagens, formas ou estilos poéticos, podem ser ensinados em qualquer momento (e principalmente, se solicitados), mas não garantem resultado poético, pois isso exige aprimoramento e domínio no trato com as palavras e seus sentidos.

Desse modo, quando enfatizamos a autoria no encontro poesia e criança, não estamos nos referindo ao propósito de "formar" poetas, mas ao fazer de conta, ao brincar de ser poeta. Estamos principalmente enfatizando a ludicidade que caracteriza a leitura, a fruição e a criação poética com crianças e a criação de poemas como estratégia de aproximação entre poesia e leitor. Outros pesquisadores partilham a ideia de "fazer poesia" na escola, como Parr e Campbell (2006), que falam de "poetas na prática", de alunos e professores que não se limitam a aprender sobre poesia e buscam construir uma atitude poética de aprendizados dos seus processos e produtos, que acreditam no poder da poesia como ferramenta de aprendizado. Para os autores, a palavra poética provoca uma gama de emoções, e precisamos escrevê-la.

A experiência de escrever poesia pode ser recebida a princípio com recusa, como um "não sei fazer" ou um "não sei por onde começar", tanto pelas crianças quanto pelos adultos. Parr e Campbell (2006) observaram nas oficinas de criação poética com professores que à medida que é superada a relutância inicial, estes se tornam capazes de expressar seus pensamentos, ideias e opiniões de forma criativa, evocar um forte senso de imagens poéticas, compartilhar com seus leitores e, o mais importante, os "poetas" iniciantes concluem o exercício com uma sensação de sucesso.

Para os autores, a confiança que o professor adquire ao escrever um poema pode ser fomentada no aluno. Adultos e crianças precisam da poesia para poder observar melhor, ponderar, fazer perguntas, descobrir imagens, sons e sentimentos que poderiam permanecer inexplorados sem o contato com ela. A poesia traz equilíbrio e beleza ao nosso mundo, cada vez mais complexo. Nós 
entendemos que "fazer poesia" é um modo de "brincar de ser poeta", uma excelente estratégia de aproximação da poesia e da experiência estética.

Pensando a formação necessária para trabalhar a literatura na infância e em especial a poesia, algumas universidades têm colocado a temática no currículo do curso de Pedagogia. A Universidade Federal de Santa Catarina (UFSC) é uma delas. A disciplina "Literatura e Infância" dedica uma das unidades: à palavra poética e às suas possibilidades de trabalho com as crianças; à palavra poética e à sua importância para a sensibilidade leitora das crianças; à diferença entre poema e poesia, contemplando a estrutura que compõe o poema: rima, verso e ritmo; e, ainda, a conhecer os principais escritores que se dedicam a escrever poesia para crianças.

Debus e Cintra (2012, p. 158) destacam, no trabalho com essa disciplina, a leitura brincante de poemas. As atividades propostas aos futuros professores e professoras visam, numa atmosfera de oficina poética, brincar com os poemas e instigá-los a criar e recriar poemas lidos, esperando que, em alguma medida, essas vivências possam estar presentes na abordagem com seus futuros alunos.

Exemplificando a metodologia citada, Debus e Cintra (2012, p 159), em "O poema tem sonoridade: Brincando com o som", utilizaram o livro Amanhecer na roça de Ronaldo Simões, que apresenta frases curtas que rimam com animais, para criar situações de rima com as sugestões da professora, ela fala: "Oi", e o grupo responde "boi"; fala "Bom dia", o grupo responde "cutia"; "Sai do ninho", o grupo responde "passarinho" e assim por diante. Na sequência a turma é dividida em grupos menores com o intuito de criar versos para depois a turma adivinhar, frases que rimem com cores, frutas, cidades, profissões, entre outros. Alguns exemplos dos versos criados pelas equipes em torno de: 1) Nomes de cidades de Santa Catarina (Brasil): Virginia gosta de própolis: Florianópolis; Tem no mar de montão: Tubarão; Mariana gosta de goiaba: Joaçaba; 2)Versos que se referem a Brinquedos de Crianças: Anda e rola: bola; Ela é sapeca: boneca; Gira rápido no chão: pião; 3) Versos associados à Cores: doce de marmelo: amarelo; Ele bebe que nem funil: anil; Danço com meu tamanco: branco; 4) Versos que rimam com Flores: Vejam que prosa!: rosa; Que manhã florida!: margarida; Voa borboleta: violeta.

Outra estratégia de trabalho parte da leitura do poema "Coisas" de Maria Dinorah, que trata das coisas boas, das coisas lindas, das coisas de todos e das coisas de poucos, pensar, falar e escrever três "Coisas Grandes: cabelo da Mariana, floresta amazônica e barriga da Joyce [...] Coisas Quentes: beijo, sol e cobertor [..., Coisas Femininas: sutiã, calcinha e salto alto" (DEBUS; CINTRA, 2012, p. 164) e assim sucessivamente, com três coisas coloridas, infantis, cheirosas, entre outras. A vivência de um processo de criação poética com as acadêmicas além de indicar (futuras) estratégias de trabalho com as crianças, ajudam a compor um repertório com diferentes formas poéticas. Para Debus e Cintra (2012, p. 163): "No trabalho com as crianças, é importante esse tipo de repertório, pois elas perceberão, aos poucos que o poema nem sempre tem rimas, que as palavras se insinuam e entram no ritmo do texto, obedecendo as regras de quem as escreve. 


\section{CONCLUSÕES}

Gostar de poesia e partilhar com os outros esse prazer implica, antes de tudo, que professores sejam, eles próprios, leitores de poesia. Parafraseando Bastos (1999), dificilmente se ama o que se desconhece e, para transmitir uma emoção, é necessário senti-la. Experimentar e fruir a poesia em sala de aula requer mediadores, eles próprios leitores de poesia, e com formação científica e pedagógica que os fundamente. O exercício lúdico da leitura poética instiga os estudantes do curso de Pedagogia a apropriarem-se da desenvoltura, mesmo que preliminar, necessária para experienciar atividades que incluam poesia e crianças.

O diálogo com os docentes nos mostrou que a poesia está na escola. Se ela está ainda numa proporção menor do que a desejada, as experiências relatadas mostram que estamos avançando na qualificação das práticas, com acesso a acervos significativos e notando um crescente interesse, por parte dos professores, de usufruir do capital cultural que a poesia abarca. Desse modo, meninos e meninas são convidados cada vez mais a ler, brincar, fruir e fazer poesia no espaço da sala de aula. $O$ curso de Pedagogia faz a formação inicial, sensibiliza e encoraja os futuros professores a formar um repertório poético e a transpor para a prática o aprendizado.

O movimento de mediar o trabalho com a poesia acaba por tornar-se uma oportunidade de busca e criação de estratégias de trabalho que, por decorrência, potencializam o aspecto formativo, o processo de letramento literário do professor e da professora, no ato de planejar as atividades, realizálas e refletir sobre elas. As professoras entrevistadas fizeram menção a inserir pelo menos uma vez por semana a poesia na escola. $\mathrm{O}$ argumento mostra que a poesia começa a ganhar um espaço legítimo e planejado dentro da rotina de trabalho escolar, com o reconhecimento, por parte dos docentes, do valor pedagógico e formativo da poesia, superando o âmbito da eventualidade.

Uma das professoras falou algo que nos fez refletir. Ela disse: "Na minha sala sempre tem muito barulho, eu costumo dizer mesmo que na leitura dos poemas sempre há barulho, tem trânsito. Eles [os alunos e alunas] vão ler uma quadra, vão ficar atentos e vão..." (Prof. ${ }^{a}$ C, dez. 2015) - como a professora não concluiu o pensamento, nós "devaneamos". Apreciando a atitude poética e reflexiva da interlocutora, complementamos: eles vão vibrar? Se emocionar, rir, chorar, se mexer, ter ideias, sugerir que o poema poderia ser diferente, quererão escrever outro poema, bem parecido com aquele lido, ou então bem diferente.

Ler poesia na sala de aula é planejamento criterioso, mas também uma experiência que por vezes pode ser "barulhenta", no sentido próprio e metafórico da palavra. Essa leitura pode nos tirar do lugar comum e precisamos estar dispostos a acompanhar o movimento. Assim, em se tratando da sala de aula, a primeira coisa que um professor ou uma professora que pretende promover o encontro "poesia e criança" não pode ter é medo do barulho, do barulho silencioso e do silêncio barulhento. Decididamente não é possível ler, fruir e fazer poesia na sala de aula, ou em qualquer outro lugar, sem movimento e ruído. Poesia é som, ritmo e movimento; é brincadeira e imaginação; é, sobretudo, conhecimento do homem sobre si mesmo e em relação ao outro. Ela, a poesia, está "escondida" no 
professor e na professora adultos que "perderam" o desenho, "esqueceram" a brincadeira e "contiveram" seus movimentos (DEBUS; CINTRA, 2012), mas, basta um poema brincante para (re)encontrar a ludicidade que o adulto finge que esquece quando cresce.

Ribeiro (2007, p. 56) explica que, ao contrário do que se supõe, a poesia "situa-se no campo da razão prática e não é mero exercício linguístico que nada comunica de substancial". Para o autor, é importante fazer uma reflexão sobre "o lugar que o texto poético tem ocupado na educação escolar, bem como perspectivar o lugar que, por direito aí lhe deve ser atribuído [...]" (p. 53). Os relatos das professoras explicitam que o lugar da poesia na escola começa a ser reconhecido, ocupado e ampliado. Todavia, é um trabalho que está apenas começando. A poesia ainda precisa conquistar maior espaço de reflexão e ação na formação inicial e continuada dos docentes. Algumas estratégias aqui compartilhadas desempenham o papel de mostrar primeiro que elas vêm ocorrendo e segundo que, na prática, estas estratégias ressaltam o valor pedagógico e o valor formativo da poesia, e que estes podem afetar substancialmente o campo da educação.

\section{REFERÊNCIAS}

1. AVERBUCK, Lígia Morrone. A poesia e a escola. In: ZILBERMAN, Regina. (Org.). Leitura em crise na escola: as alternativas do professor. 4 ed. Porto Alegre: Mercado Aberto, 1985. p. 63-83.

2. BALÇA, Ângela; SOUZA, Renata Junqueira de. Políticas públicas de leitura em Portugal e Brasil: novos caminhos, velhos problemas. Educação, Porto Alegre, v. 35, n. 3, p. 371-379. 2012.

Disponível em: <http://revistaseletronicas.pucrs.br/ojs/index.php/faced/article/view/11771/8394>. Acesso em: 18 jan. 2018.

3. BALLESTEROS, Elena Gómez-Villalba. Didáctica de la poesía en la Educación Primaria. Revista Interuniversitaria de Formación del Profesorado, Zaragoza, n. 18, dec. 1993, p. 107-115.

4. BASTOS, Glória. Literatura infantil e juvenil. Lisboa: Universidade Aberta, 1999.

5. BOCHECO, Eloí. Poesia infantil: o abraço mágico. Chapecó: Argos, 2002.

6. BORDINI, Maria da Glória. Troca de ideias: poesia se ensina? 2016. Disponível em: <http://www.ceale.fae.ufmg.br/pages/view/troca-de-ideias-poesia-se-ensina.html>. Acesso em: 18 jan. 2018.

7. BOURDIEU, Pierre. O poder simbólico. Lisboa: Difel, 1994.

8. CERRILLO, Pedro C. El archivo de la memoria: el cancionero infantil en la escuela. Educación y Biblioteca, Salamanca, v. 160, p. 78-81, 2007. Disponível em 
<http://gredos.usal.es/jspui/bitstream/10366/119372/1/EB19_N160_P78-81.pdf>. Acesso em: 17 jan. 2018.

COSSON, Rildo. Letramento literário: teoria e prática. 2 ed. São Paulo: Contexto, 2012.

CUNHA, Leo. O livro de poesia infantil: desafios e tendências. In: (Org.). Poesia para crianças: conceitos, tendências e práticas. Curitiba: Positivo, 2013. p. 57-80.

DEBUS, Eliane Santana Dias; CINTRA, Simone Cristiane Silveira. Literatura infantil e prática educativa: fruição e criação poética de educadores e crianças. In: Semana Antonieta de Barros: Literatura E Ensino Na Educação Básica, 2, 2012, Florianópolis. Anais. Florianópolis: LF, 2012. v. 1. p. 154-178.

DOMINGUES, Cristiane Lumertz Klein; EBERT, Síntia Lúcia Faé. Leitura e formação de leitor: a poesia para uma educação da sensibilidade. Ciências \& Letras, Porto Alegre, n. 55, p. 52-66, jan./jun. 2014.

LINABERGER, Mara. Poetry top 10: a foolproof formula for teaching poetry. The Reading Teacher, v. 58 , n. 4 , p. 366-372, dec./jan. 2004.

14. MELO, Isabel Maria Pinto do Souto. Da poesia ao desenvolvimento da competência literária: propostas metodológicas e didáticas para o ensino-aprendizagem da língua portuguesa nos $1 .^{\circ}$ e $2 .^{\circ}$ Ciclos do Ensino Básico. 429 f. Tese (Doutorado em Estudos da Criança) - Instituto de Educação, Universidade do Minho, Braga, 2011.

NOVAIS, Carlos Augusto. Elementos de composição poética: noções básicas. In: CUNHA, Leo. (Org.). Poesia para crianças: conceitos, tendências e práticas. Curitiba: Positivo, 2013. p. 13-33.

PARR, Michelann; CAMPBELL, Terry. Poets in practice. International Reading Association, v. 60, n. 1, p. 36-46, 2006. Disponível em: <http://www.readwritethink.org/professionaldevelopment/professional-library/poets-practice-20938.html>. Acesso em: 17 jan. 2018.

PINHEIRO, Helder. Poesia na sala de aula. 2 ed. João Pessoa: Ideia, 2002.

RAMOS, Ana Margarida. Dos sons aos sentidos - o texto poético para a infância e a juventude. In: Livros de Palmo e Meio: reflexões sobre literatura para a infância. Lisboa: Editorial Caminho, 2007. p. 79-33.

RIBEIRO, João Manuel de Oliveira. A poesia no primeiro ciclo do ensino básico: das orientações curriculares às decisões docentes. 173 f. Dissertação (Mestrado em Supervisão Pedagógica e 
Formação de Formadores) - Faculdade de Psicologia e de Ciências da Educação, Universidade de Coimbra, Coimbra, 2009.

20 51-81, 2007

21. crianças: conceitos, tendências e práticas. Curitiba: Positivo, 2013, p. 13-33.

22. AZEVEDO, Fernando (Coord.). Língua materna e literatura infantil: elementos nucleares para professores do ensino básico. Lisboa: Lidel, 2006. p. 47-54.

\section{Rosilene de Fátima Koscianski da Silveira:}

Graduada em Pedagogia pela Universidade do Contestado (UnC) - Campus Canoinhas; Mestre em Educação pela Universidade do Extremo Sul Catarinense (UNESC); Doutora em Educação pela Universidade Federal de Santa Catarina (UFSC), com Estágio Científico Avançado no âmbito de Doutoramento em Estudos da Criança na Universidade do Minho, Braga, Portugal. É membro dos grupos de pesquisa: Literalise: Grupo de pesquisa em literatura infantil e juvenil e práticas de mediação literária (UFSC), GIPPPGE: Grupo Internacional de Pesquisa em Políticas, Práticas e Gestão da Educação (UPE), LITTERA: Correlações entre cultura, processamento e ensino: a linguagem em foco e Grupo de Pesquisa em Arte: GPA (UNESC). Atua como professora na Rede Pública Estadual de Santa Catarina e no Curso de Pedagogia - Plano Nacional de Formação dos Professores da Educação Básica (PARFOR) - na Universidade do Sul Catarinense (UNISUL).

\section{Eliane Santana Dias Debus:}

Possui graduação em Letras Licenciatura Português e Inglês pela Fundação Educacional de Criciúma (1991), mestrado em Literatura pela Universidade Federal de Santa Catarina (1996) e doutorado em Lingüística e Letras pela Pontifícia Universidade Católica do Rio Grande do Sul (2001). Atualmente é professora da Universidade Federal de Santa Catarina, atuando no Departamento de Metodologia de Ensino e no Programa de pós-Graduação em educação.. É líder do Grupo de Pesquisas LITERALISE: Grupo de pesquisa em literatura Infantil e juvenil e práticas de mediação literária, da Universidade Federal de Santa Catarina. Tem experiência na área de Educação e Letras, com ênfase em Literatura Infantil e Juvenil, atuando principalmente nos seguintes temas: literatura infantil e juvenil, temática africana e afro-brasileira na literatura infantil e juvenil, formação de leitores, formação de professores e leitura literária. 


\section{Fernando José Fraga de Azevedo:}

Possui doutorado em Análise Textual pela Universidade do Minho (2002). Concluiu a Agregação - em 2012. É Professor Associado na Universidade do Minho. Atua na área de Humanidades com ênfase em Línguas e Literaturas.

\section{Como citar este documento:}

KOSCIANSKI DA SILVEIRA, Rosilene de Fátima; DEBUS, Eliane Santana Dias; FRAGA DE AZEVEDO, Fernando José. A POESIA: ESTRATÉGIAS PARA EXPERIMENTAR E FRUIR EM SALA DE AULA. Reflexão e Ação, Santa Cruz do Sul, v. 26, n. 2, ago. 2018. ISSN 1982-9949. Disponível em: $<$ https://online.unisc.br/seer/index.php/reflex/article/view/11601>. Acesso em: doi:http://dx.doi.org/10.17058/rea.v26i2.11601. 